Economics Series

No. 121, November 2011

\title{
An Evaluation of Overseas Oil Investment Projects Under Uncertainty Using a Real Options Based Simulation Model
}

Lei Zhu, ZhongXiang Zhang, and Ying Fan

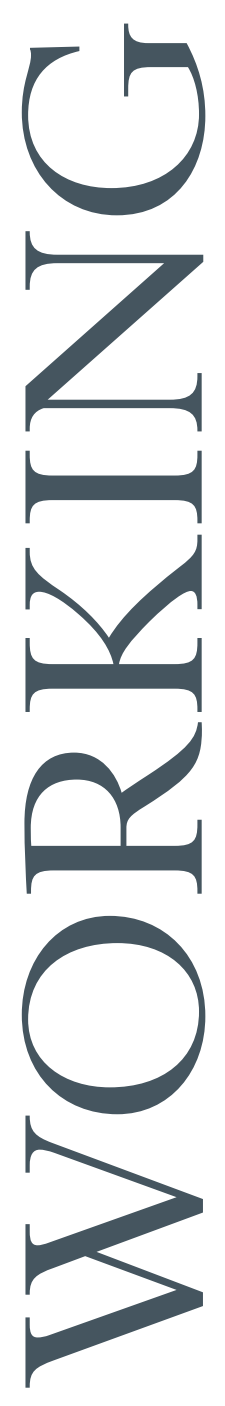


The East-West Center promotes better relations and understanding among the people and nations of the United States, Asia, and the Pacific through cooperative study, research, and dialogue. Established by the U.S. Congress in 1960, the Center serves as a resource for information and analysis on critical issues of common concern, bringing people together to exchange views, build expertise, and develop policy options.

The Center's 21-acre Honolulu campus, adjacent to the University of Hawai'i at Mānoa, is located midway between Asia and the U.S. mainland and features research, residential, and international conference facilities. The Center's Washington, D.C., office focuses on preparing the United States for an era of growing Asia Pacific prominence.

The Center is an independent, public, nonprofit organization with funding from the U.S. government, and additional support provided by private agencies, individuals, foundations, corporations, and governments in the region.

East-West Center Working Papers are circulated for comment and to inform interested colleagues about work in progress at the Center.

For more information about the Center or to order publications, contact:

Publication Sales Office

East-West Center

1601 East-West Road

Honolulu, Hawai‘i 96848-1601

Telephone: 808.944 .7145

Facsimile: 808.944.7376

Email: EWCBooks@EastWestCenter.org

Website: EastWestCenter.org 
VE $\frac{\text { EA S T - W ES T C E N T E R }}{\text { collaboration - expertise + leadership }}$

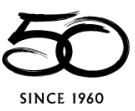

SINCE 1960
Economics Series

No. 121, November 2011

\section{An Evaluation of Overseas Oil Investment Projects Under Uncertainty Using a Real Options Based Simulation Model}

Lei Zhu, ZhongXiang Zhang, and Ying Fan

Lei Zhu is an assistant professor at the Center for Energy and Environmental Policy Research, Institute of Policy and Management, Chinese Academy of Sciences, Beijing, China

ZhongXiang Zhang is a senior fellow at the East-West Center. Currently, he is a co-editor of both Environmental Economics and Policy Studies (the official journal of the Society of Environmental Economics and Policy Studies) and International Journal of Ecological Economics and Statistics, and serves on the editorial boards of nine leading international journals and two Chinese journals.

Ying Fan is a professor and director at the Center for Energy and Environmental Policy Research, Institute of Policy and Management, Chinese Academy of Sciences, Beijing, China.

East-West Center Working Papers: Economics Series is an unreviewed and unedited prepublication series reporting on research in progress. The views expressed are those of the author(s) and are not necessarily those of the East-West Center. Working Papers are available for free in PDF format on the Center's website at EastWestCenter.org/ewcworkingpapers. To order print copies (\$3.00 each plus shipping and handling), contact the Center's Publication Sales Office. 


\title{
An evaluation of overseas oil investment projects under uncertainty using a real options based simulation model
}

\author{
Lei Zhu ${ }^{a}$, ZhongXiang Zhang ${ }^{\text {b,* }}$, Ying Fan ${ }^{\text {a }}$ \\ ${ }^{a}$ Center for Energy and Environmental Policy Research, Institute of Policy and Management, Chinese Academy of \\ Sciences, Beijing 100190, China \\ ${ }^{\mathrm{b}}$ Research Program, East-West Center, 1601 East-West Road, Honolulu, HI 96848-1601, USA
}

\begin{abstract}
This paper applies real options theory to establish an overseas oil investment evaluation model that is based on Monte Carlo simulation and is solved by the Least Squares Monte-Carlo method. To better reflect the reality of overseas oil investment, our model has incorporated not only the uncertainties of oil price and investment cost but also the uncertainties of exchange rate and investment environment. These unique features have enabled our model to be best equipped to evaluate the value of oil overseas investment projects of three oil field sizes (large, medium, small) and under different resource tax systems (royalty tax and production sharing contracts). In our empirical setting, we have selected China as an investor country and Indonesia as an investee country as a case study. Our results show that the investment risks and project values of small sized oil fields are more sensitive to changes in the uncertainty factors than the large and medium sized oil fields. Furthermore, among the uncertainty factors considered in the model, the investment risk of overseas oil investment may be underestimated if no consideration is given of the impacts of exchange rate and investment environment. Finally, as there is an important tradeoff between oil resource investee country and overseas oil investor, in medium and small sized oil investment negotiation the oil company should try to increase the cost oil limit in production sharing contract and avoid the term of a windfall profits tax to reduce the investment risk of overseas oil fields.
\end{abstract}

Keywords: Overseas oil investment, Project value, Real options, Least Squares Monte-Carlo

JEL Classification: Q41; Q43; Q48; G31; O13; O22; C63

\footnotetext{
* Corresponding author: ZhongXiang Zhang, Senior Fellow, Research Program, East-West Center, 1601 East-West Road, Honolulu, HI 96848-1601, USA. Tel.: +1-808-944 7265; fax: +1-808-944 7298. E-mail address: ZhangZ@EastWestCenter.org.
} 


\section{Introduction}

Rapid economic growth in emerging economies like China and India has led to a huge increase in oil imports. This has raised great concern regarding their energy security. As a response, these countries have supported the expansion of their oil companies as an integrated part of energy strategies to address their growing dependence on imported oil. In their view, compared to oil trading, overseas oil investment can provide a more stable oil supply to enable them to ease pressure on their domestic energy supply and can thus offset to some extent the adverse effects of high oil prices on their economies. However, the extent to which this would enhance their energy security is a matter of dispute, because these oil companies do not necessarily send the oil that they produce overseas back to home countries. Instead, they prefer to let market considerations dictate where it is sold. But, there is a great consensus that investments in oil fields overseas help to stabilize the oil prices by pumping more oil out of the fields and enlarging the overall availability of oil on the world market. With the world's oil use set to rise, companied with increasing world's oil prices, adding new capacities to world oil supplies via oil overseas investment is seen as beneficial to all, and needs thus to be encouraged and appreciated. Thus, the real issue is not about where the oil produced from overseas investment goes. Rather, it is overseas investment itself. While such an investment will benefit oil users, whether it is in the best interests of investors needs a careful evaluation, particularly given large capital investment involved in and a very long duration of an oil investment project.

In conventional investment project evaluation, commodity price uncertainty is always used to reflect the project uncertainty. For oil reserves valuation, oil price is always be used to reflect oil project uncertainty, and in most cases it is the only uncertainty which is considered in oil reserves valuation. In our opinion, only take oil price uncertainty

into account can not fully capture the complexity of overseas oil investment. In general, overseas oil investment has the same properties as that of foreign direct investment (FDI) in that the development of overseas oil fields is associated with large capital budgets, a long construction period, and high investment uncertainty. However, the decision process for overseas oil investment is more complex than that of FDI. A number of uncertainty factors should be considered in valuing overseas oil investments as the development is mainly carried out through international or state-owned oil companies with the added complication of the investee country's resource tax system.

No doubt, oil price is one of the most important factors affecting oil investment because oil is both a fundamental resource for economic growth and an international commodity. In recent years, as the dependence on foreign oil in major developed and developing countries has been increasing, and oil obtained by these countries has been mainly through direct trade, fluctuations in international oil prices have been directly transmitted to the cost of imported oil, subsequently causing adverse impacts on domestic economic growth. In the future, the reduction of proven oil reserves and the depletion of oil resources worldwide will cause oil prices to fluctuate more than before.

Another factor that needs to be considered is oil investment cost. At the initial stage of overseas oil development, the oil company signs a contract with an investee country's government or company to specify the oil field size, investment amount (capital budget), and oil extraction volume. However, in terms of the actual oil development activities, as a large-scaled project with sequential investment, there are various uncertainties in the construction of the oil project, such as uncertain length of construction, unknown geological conditions of oil deposits, and diversity among different exploitation technologies. While these uncertainty factors should be reflected in the investment cost to complete the construction of the overseas oil project, they are hard to estimate, thus affecting the total investment cost projection.

Exchange rates matter too because exchange rates are the linkage between overseas investment and domestic 
investors. Nearly all overseas investments are denominated in United States (U.S.) dollars. For oil companies, changes in exchange rates between the U.S. dollar and the domestic currency directly affect the capital budget and cash flow in the overseas oil investment. The study by Fan et al. (2008) shows that there exist a spillover effect between exchange rates and oil prices. Theoretically, when the U.S. dollar falls, the dollar-denominated crude oil price is lower against other currencies, which pushes up the crude oil price to some extent, and vice versa. In recent years, the weakness of the U.S. dollar has increased the downside risks of future U.S. dollar exchange rates, causing oil companies to take greater risk of exchange losses in overseas oil revenue accounting. Therefore, exchange rates are an important consideration in overseas oil investment valuation.

Furthermore, given that an overseas oil development project lasts 20 years or more, investee country investment environment is even more crucial to the collaboration between investor and investee in overseas oil investments. During this period, changes in the investee country's investment environment affect the risk and benefit of the overseas oil investment. And if the investee countries' investment environment deteriorates, this causes additional operation costs and may even offset the imported oil cost-dilution effect through overseas investment.

In overseas oil investment activities, the aforementioned uncertainty factors do not exist independently. Rather they are interrelated. On one hand, from the perspective of imported oil, as oil and other international commodities are denominated in U.S. dollars, a falling U.S. dollar pushes up the crude oil price to some extent. As oil is a fundamental resource for economic development, increasing oil prices push up the cost for the whole society, ${ }^{1}$ resulting in a series of social conflicts such as rising unemployment and social unrest, thus affecting the investment environment. On the other hand, from the perspective of international trade, as the U.S. dollar is an international currency, changes in the U.S. dollar exchange rate directly affect other countries' imports and exports. In particular, depreciation of the U.S. dollar increases inflationary pressures on other countries, thus affecting domestic production and eventually transmitting to the investment environment.

Therefore, to more accurately evaluate the risks and benefits of overseas oil investment, a proper overseas oil investment evaluation method is needed for oil companies to address these uncertainty factors and consider their complex interrelationships, including the impact of different resource taxes. This paper applies real options theory to establish an overseas oil investment evaluation model based on Monte Carlo simulation, and is solved by the Least Squares Monte-Carlo method (LSM). Several uncertainty factors most relevant to overseas oil investment are considered, including not only the oil price and investment cost, but also the exchange rate and investment environment. The model can evaluate the value of oil fields of different sizes (large, medium, small) and under different resource tax systems (royalty tax and production sharing contracts).

The remainder of the paper is organized as follows. Section 2 provides a literature review. Section 3 describes our model. Section 4 undertakes a case study of an overseas oil investment project under a variety of uncertainty factors. Section 5 presents main conclusions and suggestions for further research.

\section{Literature review}

Myers (1977) and Ross (1978) were the first to introduce a "real" financial option pricing approach. In this approach, investors use the efficient market hypothesis, portfolio theory, and trading strategies to value streams generated by risky assets under available market information. Because the value of options is real, the greater the future uncertainty, the greater the project value should be. Myers (1984) pointed out that discounted cash flow techniques have weaknesses in evaluating investments with significant managerial flexibility, and consequently

\footnotetext{
${ }^{1}$ The exact effects of oil price increase depend on whether there is a price control and the transmission mechanisms through which price affects spread into the economy (Wu et al., 2010 and 2011).
} 
people tend to use either decision analysis or the option pricing approach when evaluating these kinds of investments. When McDonald and Siegel (1986) first developed a real options valuation model, they assumed that both the project value and the investment followed geometric Brownian motion and used the option pricing approach to solve. Brennan and Schwartz (1985) first introduced a real options approach to natural-resource investment and presented a way of valuating an asset with great volatility in its output commodity price. Assuming that the price of minerals followed geometric Brownian motion, they used real option model to define the optimal management strategy for a mine, including mine evaluation by replicating the portfolio to determine permanent abandonment and temporary closure rules under uncertainty.

Recent real option studies trend to study the compound option structures and the relationship between investment and uncertainty. Kulatilaka and Perotti (1998) had provided a strategic rationale for growth options under uncertainty and imperfect competition. They had pointed out that higher uncertainty means more opportunity rather than simply larger risk and their results contradict the view that volatility was a strong disincentive for investment. Sarkar (2000) had shown that in certain situations, an increase in uncertainty could actually increase the probability of investing, and thereby has a positive impact on investment. Smit and Trigeorgis (2004) had presented an approach that integrated real options and game theory to strategic investment. Their treatment of strategic investment extended the potential of real options by combining it with game theory to capture the competitive dimensions and endogenous interactions of strategic decisions between the firm and its competitors. Copeland and Antikarov (2005) attempted to provide the foundation for establishing a consensus on methodology. They had proposed an outline of a standard procedure and presented a five-step solution process (marketed asset disclaimer, MAD approach) for defining real options and for valuing corporate projects in which such options were an important source of expected value.

To date, many studies have applied the real options approach to evaluate natural-resource investments, but most of them have focused on the evaluation of individual projects. Paddock et al. (1988) developed a model of offshore oil leases and used it to define optimal investment rules for undeveloped offshore oil reserves. They thought that the option pricing approach had the following three advantages over the discounted cash flow method: first, it requires significantly less data because it uses market information efficiently; second, it incurs less computational cost and is less subject to error; third, it provides a guide for the optimal timing of development. Based on work by Smith and Nau (1995), Smith and McCardle $(1998,1999)$ used decision analysis based on dynamic programming and option pricing theory to study the issue of the valuation of oil resources. Using a model of an oil property, they studied the optimal suspension, decision-making for exploration and development, and the optimal time to invest. They also considered other effects on oil-property valuation, such as production control and decision-makers' attitudes towards risk. Conrad and Kotani (2005) took the perspective of social benefit, applying the real option approach to evaluate the social net benefit of Arctic National Wildlife Refuge. In their model they had discussed the impact of two oil price processes (geometric Brownian motion and mean-reversion process) on optimal development time for oil project. Schwartz and Trolle (2010) had developed a model for pricing expropriation risk in oil projects. The model was used to investigate, under the uncertainty of oil price, the option value that the government had to expropriate oil resource from the oil company during oil project development period. And the model is solved by Least Squares Monte-Carlo (LSM) method.

The real options approach is well suited to estimate future uncertainty in natural-resource investments. Brennan and Schwartz (1985) and Paddock et. al (1988) assumed that commodity prices follow geometric Brownian motion and that a project's future volatility depended only on its commodity output price volatility. Smith and McCardle 
(1998) assumed that both oil prices and oil productivity followed geometric Brownian motion, so that the project's future volatility involved the integration of oil-price and productivity uncertainties. Lima and Suslick (2006) showed that among all the input parameters, future volatility was by far the most critical parameter in option pricing models. However, they did not believe that the project's future volatility could be considered equivalent to the fluctuation of its commodity output price. Rather, they estimated project volatility by considering both commodity prices and operating cost evolved as geometric Brownian motion and used their model to evaluate a hypothetical gold-mine project. The result showed that project volatility was higher than that of commodity prices except under very unrealistic industry conditions.

For a large-scaled investment project like oil overseas investment project, it will take time for an oil company to complete overseas oil investment. Thus, the investment decision can be viewed as a multi-stage project investment decision problem (Dixit and Pindyck, 1994). Majd and Pindyck (1987) thought that construction proceeds were usually flexible and could be adjusted with the arrival of new information. They used contingent claims analysis to derive optimal decision rules and to value such investments. Bar-Ilan and Strange (1996) studied the effects of investment lags of an uncertain, irreversible investment. They has pointed out that conventional results regarding the effect of price uncertainty on investment are weakened or reversed when there are lags. Aguerrevere (2003) studied the effects of competitive interactions on investment decisions and on dynamics of the price of incremental investment with time to build and operate flexibility. He found that the increase in uncertainty may encourage firms to increase their capacity and price volatility may be increasing in the number of competitors in the industry.

In this paper, we establish a real options evaluation model. Our model differs from existing oil investment study on several grounds. First, our model has good applicability for an evaluation of overseas oil investments. It is based on Monte Carlo simulation, and is solved by the Least Squares Monte-Carlo method (LSM), by which both the investment risk and project value can be calculated. It is also easy to simulate different resource tax systems in our model. Second, the framework of our simulation-based real options model makes it easy to take several uncertainty factors into account. With consideration of the complexity in overseas oil investment, our model has considered four uncertainty factors (oil price, investment cost, exchange rate, and investment environment) and the interrelationships among these uncertainty factors. Third, as large-scaled investment project, we take overseas oil investment as a multi-stage investment decision problem so that the investment option during oil investment stage has been taken into consideration. This treatment enables the investment to be more flexible and adjusted with the arrival of new information. These unique features have enabled our model to be best equipped to evaluate the value of oil overseas investment projects.

\section{The model}

This paper emphasis on the evaluation of overseas oil investment and does not consider the barriers for oil companies to enter investee (resource) countries. The evaluation includes oil project construction period and development (operation) period. It does not consider the exploration period. During the construction of oil project, the oil company can decide whether to continue investment or give up the project according to the new information at each investment stage. It has the right to exercise the abandon option to terminate the oil project in any investment stage. In general, at the initial stage the oil company will sign a contract with local government to specify the oil field development years and total investment amount. Assuming the total period for oil field development is $T$ years, for the purpose of evaluation we divide the $T$ years into $N$ periods, each with a length of $\Delta t=T / N$, 
and define $t_{n}=n \Delta t, n=0,1, \ldots N$.

\subsection{Modeling uncertainty factors}

\subsubsection{Oil prices}

Changes in oil prices will directly affect the benefit of overseas oil investment, therefore it has a significant impact on oil project decision. Here assuming the international oil price follows a geometric Brownian motion (Pindyck, 1997):

$$
d P_{\text {Oil }}=\alpha_{P} P_{\text {Oil }} d t+\sigma_{P} P_{\text {Oil }} d z_{P}
$$

where $P_{\text {Oil }}$ is oil price in units of U.S. dollar/Barrel; $d z_{P}$ is the independent increments of Wiener process

$d z_{P}=\varepsilon_{P} \sqrt{d t}$, where $\varepsilon_{P}$ is a normally distributed random variable with mean 0 and standard deviation 1; and $\alpha_{P}$ and $\sigma_{P}$ represent the drift and variance parameters of the oil price, respectively. In the simulations, the discrete approximation to oil price process is:

$$
P_{\text {Oil }}\left(t_{i+1}\right)=P_{\text {Oil }}\left(t_{i}\right) \exp \left(\alpha_{P} \Delta t+\sigma_{P}(\Delta t)^{1 / 2} \varepsilon_{P}\right)
$$

\subsubsection{Exchange rate}

Both oil prices and overseas investment are denominated in U.S. dollars. Changes in U.S. dollar exchange rates will to some extent affect the oil price and the overseas oil valuation. Here assuming the exchange rate follows a geometric Brownian motion (Fan and Zhu, 2010):

$$
d S_{E}=\alpha_{S} S_{E} d t+\sigma_{S} S_{E} d z_{S}
$$

where $S_{E}$ is the exchange rate between investor country's currency and U.S. dollar; $d z_{S}$ is the independent increments of Wiener process $d z_{S}=\varepsilon_{S} \sqrt{d t}$, where $\varepsilon_{S}$ is a normally distributed random variable with mean 0 and standard deviation 1; and $\alpha_{S}$ and $\sigma_{S}$ represent the drift and variance parameters of the exchange rate, respectively. And this paper also considers the correlation between U.S. exchange rate and oil price, $\rho_{P S}$ denotes the correlation coefficient between them. In the simulations, the discrete approximation to exchange rate process is:

$$
S_{E}\left(t_{i+1}\right)=S_{E}\left(t_{i}\right) \exp \left(\alpha_{S} \Delta t+\sigma_{S}(\Delta t)^{1 / 2} \varepsilon_{S}\right)
$$

\subsubsection{Investment environment (oil production cost)}

Investment environment is a necessary external condition for overseas investment activities. Our paper has added investment environment factor into oil production cost. Nordal (2001) used the real options approach to study the 
impact of risk in emerging-market countries on foreign direct investment by adding country risk to project valuation. He defined a country-state variable, and assuming that this variable followed geometric Brownian motion. Investment environment, as an important aspect of country risk, should be considered in the valuation for overseas investment with long operation period. Our paper assumes that the investment environment would mainly affect the oil production cost, and we use the uncertainty of oil production cost to represent the uncertainty of investment environment. This treatment implies that, on the one hand, the oil production cost can to some extent reflect different countries' oil quality and geographical diversity; on the other hand, that the uncertainty of future oil production cost is caused by the changes in investment environment. As we use the uncertainty of oil production cost to reflect the impact of investment environment on the overseas oil investment evaluation, here assuming the investment environment follows a geometric Brownian motion:

$$
d C_{\text {Oil }}=\alpha_{C} C_{\text {Oil }} d t+\sigma_{C} C_{\text {Oil }} d z_{C}
$$

where $C_{\text {Oil }}$ is oil production cost in units of U.S. dollar/Barrel; $d z_{C}$ is the independent increments of Wiener

process $d z_{C}=\varepsilon_{C} \sqrt{d t}$, where $\varepsilon_{C}$ is a normally distributed random variable with mean 0 and standard deviation 1; and $\alpha_{C}$ and $\sigma_{C}$ represent the drift and variance parameters of the investment environment (oil production cost), respectively. Our paper also considers the correlation among investment environment, U.S. exchange rate, and oil price, $\rho_{P C}$ denotes the correlation coefficient between oil price and investment environment (oil production cost), and $\rho_{C S}$ denotes the correlation coefficient between U.S. exchange rate and investment environment (oil production cost). In the simulations, the discrete approximation to oil production cost process is:

$$
C_{\text {Oil }}\left(t_{i+1}\right)=C_{\text {Oil }}\left(t_{i}\right) \exp \left(\alpha_{C} \Delta t+\sigma_{C}(\Delta t)^{1 / 2} \varepsilon_{C}\right)
$$

\subsubsection{Investment cost}

As a large-scaled project with sequential investment, once the oil company starts to invest in overseas oil field, at the initial stage, assuming $K_{I n v}$ is the expected total investment cost for project construction, the total investment remaining at time $t_{i}$ is $K_{I n v}\left(t_{i}\right)$. The investment expenditure of each time period is defined as $I_{I n v}$. As overseas oil investment is highly related to international oil prices, so here $I_{I n v}$ is set as a linear function of oil price, $I_{I n v}\left(t_{i}\right)=i P_{O i l}\left(t_{i}\right)$, where $i$ is oil project investment rate. It means the investment expenditure of each period will increase as the oil prices rises so it can speed up the completion of the project.

Because the capital budget of overseas oil investment is quite large, such a large investment is inevitably facing uncertainties (e.g. the uncertainties of exploration technology and oil field geological condition). These uncertainties will cause the changes in the remaining investment at each period, and that make the actual investment amount 
different from the capital budget specified in the contract. Here assuming the remaining total investment $K_{I n v}$ is uncertain in order to reflect the uncertainty of overseas oil investment cost (Dixit and Pindyck, 1994), $K_{I n v}$ follows the controlled diffusion process:

$$
d K_{I n v}=-I_{I n v} d t+\beta\left[I_{I n v} K_{I n v}\right]^{0.5} d x
$$

where $\beta$ is a scale parameter representing the uncertainty surrounding $K_{I n v}$; and $d x$ is the independent increment of Wiener process $d x=\varepsilon \sqrt{d t}$, where $\varepsilon$ is a normally distributed random variable with mean 0 and standard deviation 1. The variance of $K_{I n v}$ is $\operatorname{Var}\left(K_{I n v}\right)=\left(\frac{\beta^{2}}{2-\beta^{2}}\right) K_{I n v}{ }^{2}$, whereby uncertainty of oil investment cost reduces as $K_{I n v}$ decreases (Dixit and Pindyck, 1994). In addition, as oversea oil investment is denominated in U.S. dollars, our paper also considers the correlation between U.S. exchange rate and the remaining investment cost, with $\rho_{K S}$ denoting their correlation coefficients. In the simulations, the discrete approximation to remaining investment cost process is:

$$
K_{\text {Inv }}\left(t_{i+1}\right)=K_{I n v}\left(t_{i}\right)-i P_{\text {Oil }}\left(t_{i}\right) \Delta t+\beta\left[i P_{\text {Oil }}\left(t_{i}\right) K_{\text {Inv }}\left(t_{i}\right)\right]^{1 / 2}(\Delta t)^{1 / 2} \varepsilon_{x}
$$

This model assumes that the switching expenditure $I_{I n v}$ is a linear function of oil price $P_{\text {Oil }}$. As there does not exist any adjustment cost or other cost related to the changes of investment expenditure $I_{I n v}$, the investment rule has a bang-bang solution at any time before the oil investment is completed (Majd and Pindyck, 1987). Therefore, the optimal investment expenditure amount will either be $I_{I n v}=0$ or $I_{I n v}=I_{I n v \max }$ (Majd and Pindyck, 1987, Dixit and Pindyck, 1994, Schwartz, 2004). At the initial stage, the oil company will either take maximum switching rate $i_{\max }$ to do the oil investment or abandon the project. Therefore, under the condition of the optimal investment rule, $i=i_{\max }$. Because $K_{I n v}$ is uncertain, the time needed to complete the oil investment is uncertain, too. The actual oil investment cost can be known only after the investment has been completed, $\sum_{i=0}^{\tau} I_{\text {Inv }}\left(t_{i}\right)$, where $\tau$ is the actual time it takes to finish overseas oil investment. 


\subsection{Overseas oil investment valuation}

Assuming in overseas oil field development period, the crude oil production at $t_{n}$ period is $Q_{O i l}\left(t_{n}\right)$, and all

of the crude oil produced at $t_{n}$ period can be sold at the same period. Assuming the crude oil production capacity is constant in each period.

$r$ is the interest rate, differing across countries. Investee country's resource tax system has been added into the valuation. Oil resource tax systems can be divided into two major categories, including resource royalty and production sharing contract (PSC). Furthermore, some countries also levy windfall profits tax in domestic oil field according to oil prices change. These three resource tax systems have been modeled in our cash flow calculations.

\subsubsection{Operational value of overseas oil project}

After overseas oil investment has been completed, the project starts producing oil. At any time $t_{i}$ in oil development period, $C F\left(t_{i}\right)$ is the cash flow that the oil company can obtain through oil production and sale. Cash flows under three resource tax systems are modeled as follows:

1) Under resource royalty system, the cash flow $C F_{1}\left(t_{i}\right)$ that the oil company can obtain is represented as:

$$
C F_{1}\left(t_{i}\right)=\left[P_{\text {Oil }}\left(t_{i}\right) \cdot Q_{O i l}\left(t_{i}\right) \cdot\left(1-\operatorname{Tax}_{1}\right)-C_{\text {Oil }}\left(t_{i}\right) \cdot Q_{O i l}\left(t_{i}\right)\right] \cdot\left(1-\operatorname{Tax}_{2}\right) \cdot S_{E}\left(t_{i}\right)
$$

Where $\operatorname{Tax}_{1}$ and $\operatorname{Tax}_{2}$ are the resource royalty and income tax rate of investee country, respectively.

2) Under production sharing system, the cash flow $C F_{2}\left(t_{i}\right)$ can be represented as:

$$
\begin{aligned}
C F_{2}\left(t_{i}\right)= & {\left[P_{\text {Oil }}\left(t_{i}\right) \cdot\left(Q_{\text {Oil }}\left(t_{i}\right)-\left(Q_{\text {Oil }}\left(t_{i}\right)-c l_{\text {Oil }}\right) \cdot g_{\text {Gov }}\right)-C_{\text {Oil }}\left(t_{i}\right) \cdot Q_{\text {Oil }}\left(t_{i}\right)\right] } \\
& \cdot\left(1-\operatorname{Tax}_{2}\right) \cdot S_{E}\left(t_{i}\right)
\end{aligned}
$$

Where $\mathrm{cl}_{\mathrm{O} i l}$ is the cost oil limit under the PSC; $g_{\text {Gov }}$ is the share of investee country's government in profit oil at each period.

3) If the investee country has levied windfall profits tax, under existing production sharing system, the cash flow $C F_{3}\left(t_{i}\right)$ can obtain can be represented as:

$$
C F_{3}\left(t_{i}\right)=\left\{\begin{array}{l}
\text { if } P_{\text {Oil }}\left(t_{i}\right)>P_{\text {Tax } 3}, C F_{2}\left(t_{i}\right)-\left[\begin{array}{l}
\left(P_{\text {Oil }}\left(t_{i}\right)-P_{\text {Tax3 } 3}\right) \cdot Q_{\text {Oil }}\left(t_{i}\right) \\
\cdot \operatorname{Tax}_{3} \cdot\left(1-\operatorname{Tax}_{2}\right) \cdot S_{E}\left(t_{i}\right)
\end{array}\right] \\
\text { if } P_{\text {Oil }}\left(t_{i}\right) \leq P_{\text {Tax } 3}, C F_{2}\left(t_{i}\right)
\end{array}\right.
$$

Where $\operatorname{Tax}_{3}$ is investee country's windfall profits tax according to oil prices change, which is equal to special oil income levy tax by some oil producing countries (e.g. Venezuela). The government will levy the tax only when 
the oil price is large than threshold price $P_{\text {Tax3 }}$ of windfall profits tax.

Once overseas oil investment is completed, at any time $t_{i}$ in oil development period, the operational value for the oil company that continues to operate the oil project should be the sum of discount cash flows from $t_{i}$ to the end of development period, which can be represented as:

$$
V_{\text {Oil }}\left(t_{i}\right)=\sum_{n=i}^{N} e^{-r\left(t_{n}-t_{i}\right)} C F\left(t_{n}\right)
$$

\subsubsection{Investment value of overseas oil project}

The oil project would not generate any cash flow during construction. So the cash flows calculated in construction period can to some extent be viewed as anticipated cash flows. Under the option analysis framework, in oil project construction period, the oil company owns the abandon option. At the oil investment completed time $\tau$, the investment value of oil project is equal to that of operational value:

$$
F_{\text {Oil }}(\tau)=V_{\text {Oil }}(\tau)
$$

In any period before the oil investment is completed, if the investment needed is higher than expected oil project value, the oil company will exercise the abandon option to terminate the project to prevent more losses. The investment value of oil project can be denote as $F_{\text {Oil }}\left(t_{i}\right)$, which depends on the expected cash flows after oil investment has been completed and the cost needed to complete oil project investment. So at period $t_{i}$ before the oil investment is completed, the value of oil investment is:

$$
F_{\text {Oil }}\left(t_{i}\right)=\max \left\{0, E_{t_{i}}\left[e^{-r\left(t_{i+1}-t_{i}\right)} F_{\text {Oil }}\left(t_{i+1}\right)\right]-I_{\text {Inv }}\left(t_{i}\right)\right\}
$$

Where $E_{t_{i}}[*]$ means, at period $t_{i}$, the expected value for oil company continues to hold abandon option. As aforementioned, the investee country's government may have penalty for oil company to abandon the project in investment stage. That will also be a default loss for the company to bear. With the penalty, at period $t_{i}$ before the oil investment is completed, the value of oil investment can be rewritten as:

$$
F_{\text {Oil }}\left(t_{i}\right)=\max \left\{- \text { Pen, } E_{t_{i}}\left[e^{-r\left(t_{i+1}-t_{i}\right)} F_{\text {Oil }}\left(t_{i+1}\right)\right]-I_{I n v}\left(t_{i}\right)\right\}
$$

Where Pen is the penalty that the oil company should pay for abandoning investment project. The penalty may occur in some oil development contracts. However, because of data limitations, while we incorporate this parameter in our model, this has not considered in our empirical study. 


\subsection{LSM based model solution}

We need to estimate the value of equation (12) in order to calculate the value of oil project. As the expect value $E_{t_{i}}\left[e^{-r\left(t_{i+1}-t_{i}\right)} F_{\text {Oil }}\left(t_{i+1}\right)\right]$ is hard to determine, we apply Least Squares Monte Carlo (LSM) method to compute the expect value and oil project value.

The LSM method was developed for valuing American options and is based on Monte Carlo simulation and least squares regression (Longstaff and Schwartz, 2001; Schwartz, 2004). In the model developed here, the oil company has the abandon option before overseas oil investment is completed. And the oil company will evaluate the decision to abandon the oil investment at each discrete time point. The detail of the solution procedure is as follows.

Take $G$ as simulation paths, for any path $g$, conditional on not having abandoned oil project before, at the final date of operational period (time $N$, the last stage of operational period), the value of the oil project is given by the boundary condition:

$$
W_{\text {Oil }}\left(g, t_{N}\right)=C F\left(g, t_{N}\right)
$$

At any period $t_{i}$, for those paths along which the investment has been completed, the value of the oil project is computed recursively by:

$$
W_{\text {Oil }}\left(g, t_{i}\right)=e^{-r\left(t_{i+1}-t_{i}\right)} \cdot W_{\text {Oil }}\left(g, t_{i+1}\right)+C F\left(g, t_{i}\right)
$$

For those paths along which the investment is not completed, the conditional expected value of continuation is estimated by regression. The dependent variable is the discounted value of oil project at $t_{i+1}$ period, $e^{-r\left(t_{i+1}-t_{i}\right)} \cdot W_{\text {Oil }}\left(g, t_{i+1}\right)$, and the independent variable is the oil project anticipated cash flow at period $t_{i}$. The fitted value $\hat{W}_{\text {Oil }}\left(g, t_{i}\right)$ can be estimated by polynomial regression. ${ }^{2}$ Comparing the conditional expected value of oil project $\hat{W}_{\text {Oil }}\left(g, t_{i}\right)$ with the investment expenditure $I_{I n v}\left(t_{i}\right)$, then:

$$
W_{\text {Oil }}\left(g, t_{i}\right)=\left\{\begin{array}{l}
0, \hat{W}_{\text {Oil }}\left(g, t_{i}\right)<I_{I n v}\left(g, t_{i}\right) \\
\hat{W}_{\text {Oil }}\left(g, t_{i}\right)-I_{\text {Inv }}\left(g, t_{i}\right), \hat{W}_{\text {Oil }}\left(g, t_{i}\right) \geq I_{I n v}\left(g, t_{i}\right)
\end{array}\right.
$$

The recursion proceeds by rolling back in time and repeating the procedure until the exercise decisions at each possible exercise time along each path have been determined. The value of the oil project is then computed by starting at time zero, moving forward along each path until the final observation date of a given period or until the first stopping time occurs, discounting the resulting cash flows to time zero, and taking the average over all the paths to get the project value of overseas oil field with abandon option. For more discussion on the method used here, see

${ }^{2}$ Laguerre polynomials are applied in this regression with nine terms used in the implementation of the algorithm. The fitted value of this regression is the best linear unbiased estimator of the conditional expectation (Longstaff and Schwartz, 2001; Schwartz, 2004). 
Schwartz (2004).

$$
V_{\text {Oil }}^{E x p}\left(t_{0}\right)=\frac{1}{G} \sum_{g=1}^{G}\left(\begin{array}{l}
\sum_{n=\tau_{g}+1}^{N} e^{-r\left(t_{n}-t_{0}\right)} C F\left(g, t_{n}\right)-\sum_{n=1}^{\tau_{g}} e^{-r\left(t_{n}-t_{0}\right)} I_{I n v}\left(g, t_{n}\right), \\
\text { if path } g \text { is not abandoned } \\
\text { or } \\
-\sum_{n=1}^{\tau_{g}} e^{-r\left(t_{n}-t_{0}\right)} I_{I n v}\left(g, t_{n}\right) \text {, if path } g \text { is abandoned }
\end{array}\right)
$$

Where, at any path $g$, if the oil project is abandoned, $\tau_{g}$ is the abandon period in path $g$, else $\tau_{g}$ is the investment completed period in path $g$. LSM method described has been implemented in Matrix Laboratory (MATLAB), and all solution procedure can be seen as below:

\section{Figure 1 Procedures for Decision-making and Solution Approach}

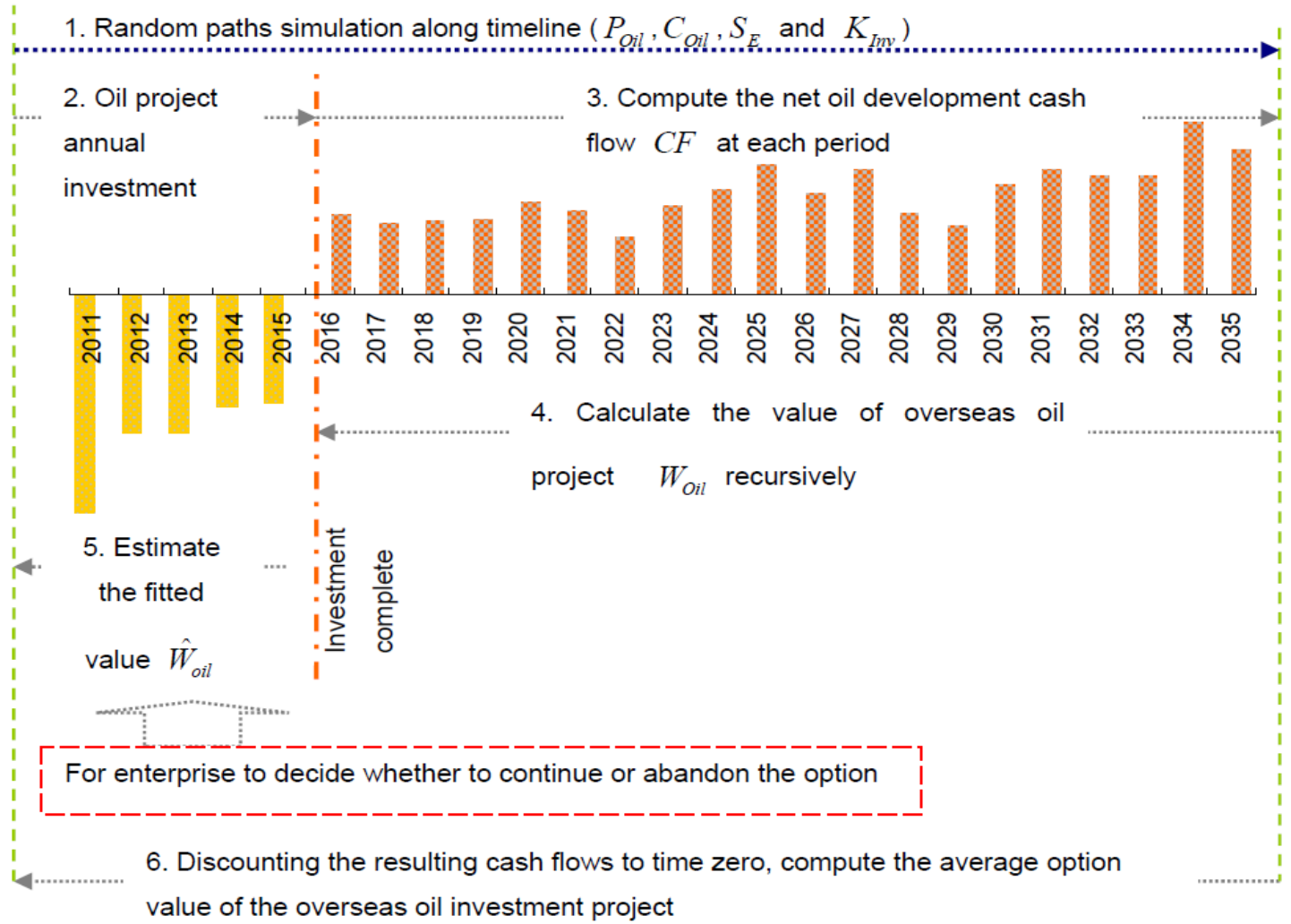




\section{A case study}

We selected an oil company in China as the overseas investor and Indonesia in Southeast Asia as the oil resource investee as the case study for the real options evaluation model proposed in this paper. We apply the model to evaluate whether China should invest in an overseas oil investment project in Indonesia, taking into consideration oil price, exchange rate, investment environment, and oil investment cost uncertainties, and the impacts of different resource tax systems.

\subsection{Model parameters}

Table 1 shows the parameter values of the model. The data is based on the year 2006. It should be noted that it is difficult to quantify the fluctuation of an investee country's investment environment. We use the consumer price index (CPI) as a reflection of a country's degree of policy stability in accordance with Fan and Zhu (2010). Some oil-investee countries have highly unstable policies which often lead to huge price fluctuations and deterioration of the investment environment. Therefore, the investee country's CPI volatility is used as a proxy variable to reflect changes in its investment environment.

Because of the lack of comprehensive overseas oil investment data, we refer to the research of Blake and Roberts (2006), who suggest evaluating three typical sized oil fields (large, medium, small). Table 1 defines all the parameters and their assumed values.

Table 1 The Parameters and the Assumed Values of the Model

\begin{tabular}{|c|c|c|c|c|}
\hline Parameter & $\begin{array}{l}\text { Model } \\
\text { symbol }\end{array}$ & Unit & $\begin{array}{l}\text { Value } \\
\text { investee } \\
\text { country }\end{array}$ & Note \\
\hline $\begin{array}{l}\text { Oil field recoverable } \\
\text { reserves-large (O-L) }\end{array}$ & \multirow{3}{*}{$R_{\text {Oil }}$} & million barrels & 300 & \multirow{6}{*}{$\begin{array}{l}\text { The data of three typical sized oil } \\
\text { fields refer to the work of Blake and } \\
\text { Roberts (2006). }\end{array}$} \\
\hline $\begin{array}{l}\text { Oil field recoverable } \\
\text { reserves-medium (O-M) }\end{array}$ & & million barrels & 150 & \\
\hline $\begin{array}{l}\text { Oil field recoverable } \\
\text { reserves-small (O-S) }\end{array}$ & & million barrels & 75 & \\
\hline $\begin{array}{l}\text { Production capacity of oil } \\
\text { field-large }\end{array}$ & \multirow{3}{*}{$Q_{\text {Oil }}$} & $\begin{array}{c}\text { million } \\
\text { barrels/year }\end{array}$ & 12 & \\
\hline $\begin{array}{l}\text { Production capacity of oil } \\
\text { field-medium }\end{array}$ & & $\begin{array}{c}\text { million } \\
\text { barrels/year }\end{array}$ & 6 & \\
\hline $\begin{array}{l}\text { Production capacity of oil } \\
\text { field-small }\end{array}$ & & $\begin{array}{c}\text { million } \\
\text { barrels/year }\end{array}$ & 3 & \\
\hline Oil prices & $P_{\text {Oil }}$ & $\begin{array}{c}\text { US } \\
\text { dollar/barrel }\end{array}$ & 60 & $\begin{array}{l}\text { WTI } 2006 \text { yearly average oil spot } \\
\text { price has been used in this work. }\end{array}$ \\
\hline Oil prices drift rate & $\alpha_{P}$ & /year & 0.02 & Set by this study. \\
\hline
\end{tabular}




\begin{tabular}{|c|c|c|c|c|}
\hline $\begin{array}{l}\text { Oil prices standard deviation } \\
\text { rate }\end{array}$ & $\sigma_{P}$ & /year & $30 \%$ & $\begin{array}{l}\text { The data refers to the estimation of } \\
\text { oil price volatility from Fan and Zhu } \\
\text { (2010). }\end{array}$ \\
\hline Exchange rate & $S_{E}$ & $\begin{array}{c}\text { US } \\
\text { dollar:RMB }\end{array}$ & 1.00:8.00 & $\begin{array}{l}2006 \text { yearly average exchange rate } \\
\text { between US dollar and RMB has } \\
\text { been used in this work. }\end{array}$ \\
\hline Exchange drift rate & $\alpha_{s}$ & /year & -0.005 & Set by this study. \\
\hline $\begin{array}{l}\text { Exchange standard deviation } \\
\text { rate }\end{array}$ & $\sigma_{S}$ & /year & $7.55 \%$ & $\begin{array}{l}\text { The data refers to the estimation of } \\
\text { exchange rate volatility from Fan } \\
\text { and Zhu (2010). }\end{array}$ \\
\hline Oil production cost & $C_{\text {Oil }}$ & $\begin{array}{c}\text { US } \\
\text { dollar/barrel }\end{array}$ & 6.64 & $\begin{array}{l}\text { Oil production cost is derived from } \\
\text { the International Energy Agency } \\
\text { (IEA) (2003). In this work, the } \\
\text { inflationary cost index published by } \\
\text { IEA (2006) was used to estimate oil } \\
\text { production cost in } 2006 \text {. }\end{array}$ \\
\hline Oil production cost drift rate & $\alpha_{C}$ & /year & 0.01 & Set by this study. \\
\hline $\begin{array}{l}\text { Oil production cost standard } \\
\text { deviation rate }\end{array}$ & $\sigma_{C}$ & \%/year & $17.85 \%$ & $\begin{array}{l}\text { The data refers to the estimation of } \\
\text { consumer price index volatility from } \\
\text { Fan and Zhu (2010). }\end{array}$ \\
\hline $\begin{array}{l}\text { Total investment cost of oil } \\
\text { field-large }\end{array}$ & & & 1730 & $\begin{array}{l}\text { The investment data of three typical } \\
\text { sized oil fields refer to the work of } \\
\text { Blake and Roberts (2006). In this } \\
\text { work the investment costs have been }\end{array}$ \\
\hline $\begin{array}{l}\text { Total investment cost of oil } \\
\text { field-medium }\end{array}$ & $K_{I n v}$ & $\begin{array}{l}\text { million US } \\
\text { dollar }\end{array}$ & 1440 & $\begin{array}{l}\text { cost index published by IEA (2006). } \\
\text { And for equivalent oil production } \\
\text { capacity, the investment cost needed }\end{array}$ \\
\hline $\begin{array}{l}\text { Total investment cost of oil } \\
\text { field-small }\end{array}$ & & & 1070 & $\begin{array}{l}\text { are larger than that of large sized oil } \\
\text { field, which will increase by } 66.47 \% \\
\text { and } 147.40 \% \text { to that of large sized } \\
\text { oil field. }\end{array}$ \\
\hline Initial annual investment-large & \multirow{3}{*}{$I_{I n v}$} & \multirow{3}{*}{$\begin{array}{l}\text { million US } \\
\text { dollar /year }\end{array}$} & 550 & \multirow{3}{*}{ Set by this study. } \\
\hline $\begin{array}{l}\text { Initial annual } \\
\text { investment-medium }\end{array}$ & & & 470 & \\
\hline Initial annual investment-small & & & 360 & \\
\hline
\end{tabular}




\begin{tabular}{|c|c|c|c|c|}
\hline Investment uncertainty & $\beta$ & & 0.5 & $\begin{array}{l}\text { Here refers to the settings in the } \\
\text { research of Schwartz (2003), Dixit } \\
\text { and Pindyck (1994). }\end{array}$ \\
\hline $\begin{array}{l}\text { Correlation between exchange } \\
\text { rate and oil price }\end{array}$ & $\rho_{P S}$ & & -0.6998 & $\begin{array}{l}\text { It is estimated through the } \\
\text { calculation between oil price and } \\
\text { exchange rate historical data. See } \\
\text { details in Fan and Zhu (2010). }\end{array}$ \\
\hline $\begin{array}{l}\text { Correlation between exchange } \\
\text { rate and oil develop cost }\end{array}$ & $\rho_{C S}$ & & -0.5490 & $\begin{array}{l}\text { It is estimated through the } \\
\text { calculation between investee } \\
\text { country's CPI and exchange rate } \\
\text { historical data. See details in Fan } \\
\text { and Zhu (2010). }\end{array}$ \\
\hline $\begin{array}{l}\text { Correlation between exchange } \\
\text { rate and oil investment }\end{array}$ & $\rho_{K E}$ & & 0.1000 & Set by this study. \\
\hline $\begin{array}{l}\text { Correlation between oil price } \\
\text { and oil develop cost }\end{array}$ & $\rho_{P C}$ & & 0.6874 & $\begin{array}{l}\text { It is estimated through the } \\
\text { calculation between oil price and } \\
\text { investee country's CPI historical } \\
\text { data. See details in Fan and Zhu } \\
\text { (2010). }\end{array}$ \\
\hline Resource royalty & $\operatorname{Tax}_{1}$ & & $0.00 \%$ & $\begin{array}{l}\text { The investee country does not levy } \\
\text { resource royalty in oil fields } \\
\text { development. }\end{array}$ \\
\hline Income tax & $\operatorname{Tax}_{2}$ & & $30.00 \%$ & $\begin{array}{l}\text { Income-tax data have been obtained } \\
\text { from the foreign-investment } \\
\text { database of the Ministry of } \\
\text { Commerce of China. }\end{array}$ \\
\hline Windfall profits tax & $\operatorname{Tax}_{3}$ & & $0.00 \%$ & $\begin{array}{l}\text { The investee country does not levy } \\
\text { windfall profit tax in oil fields } \\
\text { development. And we will discuss } \\
\text { the case of windfall profit tax in } \\
\text { results and discussions. }\end{array}$ \\
\hline Cost oil limit-large & & $\begin{array}{c}\text { million } \\
\text { barrels/year }\end{array}$ & 8 & Refer to previous oil production \\
\hline Cost oil limit-medium & $c l_{\text {Oil }}$ & $\begin{array}{c}\text { million } \\
\text { barrels/year }\end{array}$ & 4 & $\begin{array}{l}\text { sharing contracts, Here we set the } \\
\text { cost oil limit is } 2 / 3 \text { of total oil }\end{array}$ \\
\hline Cost oil limit-small & & $\begin{array}{c}\text { million } \\
\text { barrels/year }\end{array}$ & 2 & production. \\
\hline Share of government-large & \multirow{3}{*}{$g_{G o v}$} & & $80.00 \%$ & \multirow{3}{*}{$\begin{array}{l}\text { Refer to previous oil production } \\
\text { sharing contracts, Here we set the } \\
\text { government's share of profit oil is } \\
80 \% \text {. }\end{array}$} \\
\hline Share of government-medium & & & $80.00 \%$ & \\
\hline Share of government-small & & & $80.00 \%$ & \\
\hline
\end{tabular}




\begin{tabular}{|c|c|c|c|c|}
\hline Riskfree rate & $r$ & /year & $7.99 \%$ & $\begin{array}{l}\text { Investee country's long-term deposit } \\
\text { interest rate is used as a risk-free } \\
\text { rate, see details in Fan and Zhu } \\
\text { (2010). }\end{array}$ \\
\hline $\begin{array}{l}\text { Trigger oil price for windfall } \\
\text { profits tax }\end{array}$ & $P_{\operatorname{Tax}}$ & $\begin{array}{c}\text { US } \\
\text { dollar/barrel }\end{array}$ & 0 & $\begin{array}{l}\text { The investee country does not levy } \\
\text { windfall profit tax in oil fields } \\
\text { development. And we will discuss } \\
\text { the case of windfall profit tax in } \\
\text { results and discussions. }\end{array}$ \\
\hline Development period & $T$ & Year & 2006-2030 & $\begin{array}{l}\text { As the years of the contract in } \\
\text { overseas oil development always last } \\
20-25 \text { years, therefore we set the } \\
\text { development period at } 25 \text { years, } \\
\text { which can be divided into oil project } \\
\text { construction and oil field operation } \\
\text { periods. }\end{array}$ \\
\hline Time step size in simulations & $\Delta t$ & year & 1 & \\
\hline Number of simulations & $G$ & & 5000 & $\begin{array}{l}\text { In general, the simulation results } \\
\text { will start to convergence as paths } \\
\text { exceed } 1000 \text {, so the number of paths } \\
\text { simulated in different scenarios are } \\
\text { set at } 5000 \text {. }\end{array}$ \\
\hline
\end{tabular}


We use the LSM to solve our model. First, the motion paths of the oil price, exchange rate, oil production cost (investment environment), and investment cost need to be simulated. Figure 2 shows the changes of these uncertainty factors in 250 out of 5000 simulation paths. A large sample of random routing Monte Carlo simulation can simulate the result of every possible change in the uncertainty factors. We also consider the correlations between these uncertainty factors in our model to better quantify the impacts of the uncertainties on the value of the overseas oil investment.

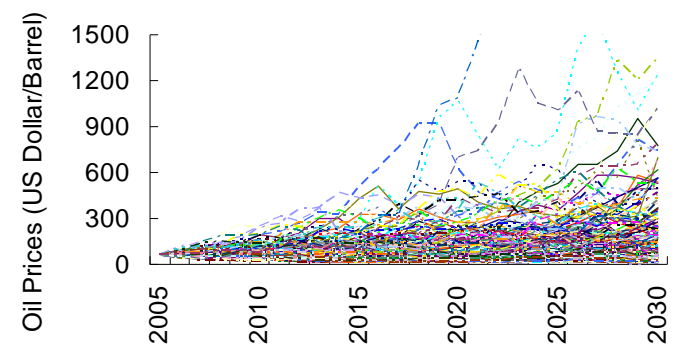

Figure 2a: Oil Prices Simulation

(Paths: 250 of 5000)

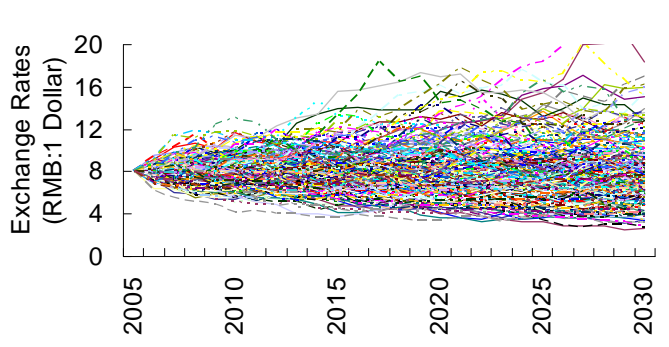

Figure 2c: Exchange Rate Simulation

(Paths: 250 of 5000)

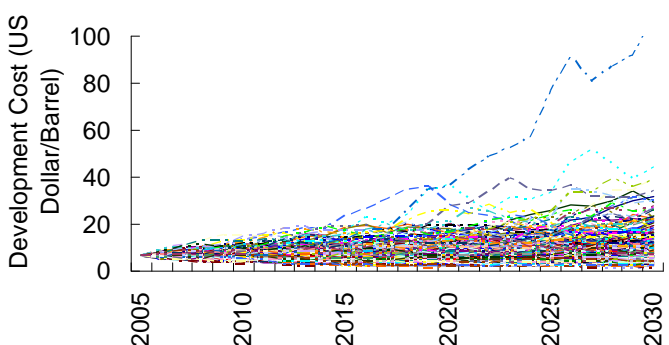

Figure 2b: Oil Production Cost Simulation

(Paths: 250 of 5000)

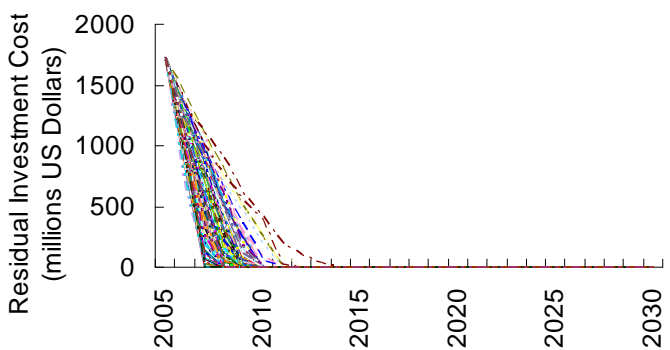

Figure 2d: Residual Investment Cost Simulation

(Paths: 250 of 5000)

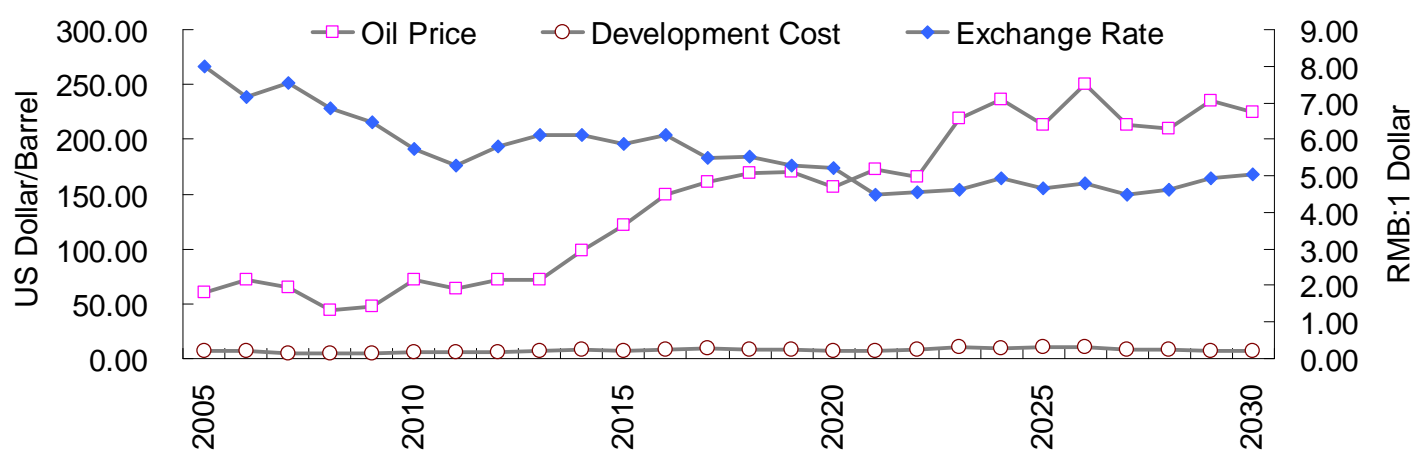

Figure 2e: Single Simulated Path of Oil Prices, Production Cost, and Exchange Rate 


\subsection{Results and discussions}

The value of overseas oil projects of different field sizes can be calculated by the LSM, taking the set parameter values into the model and simulating changes for each uncertainty factor based on their initial values. For simplicity, we use O-L, O-M, and O-S to denote oil fields with large, medium, and small recoverable reserves, respectively.

Considering the randomness of the samples in Monte Carlo simulation, in order to have a more accurate result, we calculate five seeds for each value of oil investment under different parameter settings. Each seed has a result based on 5000 simulation paths using LSM. The average of the five seeds is taken as the value of the oil investment under each parameter setting. Take O-L as an example. As shown in Table 2, taking into consideration the four uncertainty factors, the oil project value of O-L lies between 16151.83 and 17252.64 million RMB, with a mean of 16681.30.million RMB, and the expected construction time is 3.68 years. The oil investment is abandoned in only $0.144 \%$ of paths, implying that the investment risk of O-L is small.

Table 2 Oil Project Values with Different Seeds for Large Oil Field

\begin{tabular}{|c|c|c|c|c|c|c|}
\hline \multirow{2}{*}{ Investee Country } & \multicolumn{6}{|c|}{ Oil Field Size: large (O-L) } \\
\hline & Seed 1 & Seed 2 & Seed 3 & Seed 4 & Seed 5 & Average \\
\hline Project Value (Millions RMB) & 17107.15 & 16284.52 & 16610.38 & 16151.83 & 17252.64 & 16681.30 \\
\hline $\begin{array}{l}\text { Project Value of Equivalent Oil } \\
\text { Production Capacity (Millions } \\
\text { RMB/Millions Barrels per year) }\end{array}$ & 1425.60 & 1357.04 & 1384.20 & 1345.99 & 1437.72 & 1390.11 \\
\hline $\begin{array}{l}\text { Percentage of Paths Abandoned } \\
\text { (\%) }\end{array}$ & 0.180 & 0.140 & 0.100 & 0.180 & 0.120 & 0.144 \\
\hline $\begin{array}{l}\text { Project Completion Period } \\
\text { (years) }\end{array}$ & 3.69 & 3.69 & 3.69 & 3.67 & 3.64 & 3.68 \\
\hline
\end{tabular}

\subsubsection{The base case}

We first calculate the project values of the three different sizes of oil fields (O-L, O-M, O-S) in the base case, against which other cases that consider the aforementioned uncertainty factors are measured. For comparison, we also calculate their corresponding NPV values. In the NPV calculation, the four uncertainty factors are assumed to be constant, i.e., the same as their initial values, and the oil project value is the sum of the discounted cash flows and investment costs.

As shown in Table 3, for the overseas oil investment, the project values of O-L and O-M are much larger than that of O-S. The project value of equivalent oil production capacity in O-S is only $7.88 \%$ and $13.93 \%$ to that of O-L and O-M, respectively. There are two main reasons for this: First, for equivalent oil production capacity, the investment needed in O-S is much larger than that of O-L and O-M (for equivalent oil production capacity, the extra investment needed in O-S would be an increase of $147.40 \%$ and $48.61 \%$ to that of O-L and O-M, respectively); Second, the investment risks of O-L and O-M are lower than that of O-S. The percentages of paths abandoned in O-L and O-M are $0.144 \%$ and $0.360 \%$, respectively, which are much smaller than that of $19.727 \%$ for O-S. So O-L and O-M are the preferred choices in making overseas oil investment over O-S of a much greater risk. 
Table 3 Oil Project Values of Three Sizes of Oil Fields in the Base Case

\begin{tabular}{lccc}
\hline Base Case & \multicolumn{3}{c}{ Oil field size } \\
\hline Investee Country & $\begin{array}{c}\text { Large } \\
\mathbf{( O - L )}\end{array}$ & $\begin{array}{c}\text { Medium } \\
\text { (O-M) }\end{array}$ & $\begin{array}{c}\text { Small } \\
\text { (O-S) }\end{array}$ \\
\hline Project Value (Millions RMB) & 16681.30 & 4542.24 & 337.45 \\
\hline $\begin{array}{l}\text { Project Value of Equivalent Oil Production } \\
\text { Capacity (Millions RMB/Millions Barrels per }\end{array}$ & 1390.11 & 757.04 & 112.48 \\
year) & & & \\
\hline Percentage of Paths Abandoned (\%) & 0.144 & 0.360 & 19.727 \\
\hline $\begin{array}{l}\text { Project Completion Period (years) } \\
\text { NPV method }\end{array}$ & Large & Medium & Small \\
& $\mathbf{( O - L )}$ & $\mathbf{( O - M )}$ & $\mathbf{( O - S )}$ \\
\hline Project Value without Option (Millions RMB) & 6091.71 & 4.04 & -2402.99 \\
\hline $\begin{array}{l}\text { Project Value of Equivalent Oil Production } \\
\text { Capacity (Millions RMB/Millions Barrels per }\end{array}$ & 507.64 & 0.67 & -801.00 \\
year) & & & \\
\hline
\end{tabular}

Furthermore, comparing the results between real options analysis and the NPV method, we can see that the NPV values of the three different sizes of oil fields are much smaller than that of real options project values. Making an overseas oil investment is a complex process. However, the NPV method can neither consider the impacts of uncertainty factors on the value nor the flexibility of the oil investment. Therefore, the value may be underestimated using the NPV method, resulting in the possibility of an oil company missing overseas oil investment opportunities. In real options analysis, though the investment risk in O-S is much higher than that of O-L and O-M, it may to some extent be worth investing in as the project value is positive. In contrast, under the NPV method, the O-S has a negative project value, indicating that it is not worth investing in. Thus, a real option analysis can better consider the impacts of uncertainty factors on the value of overseas oil investment that may increase the estimated value of an oil project. Also the abandon option in real options analysis adds some flexibility to the project evaluation. These extra features of the real options model provide more detailed information for companies when making overseas oil investment decisions, allowing them to make more accurate judgment.

\subsubsection{The case under uncertainty of oil price levels}

As oil price is one of the most important factors in affecting overseas oil investment decision, we discuss below the impacts of different oil price levels on the value of an overseas oil project. In the base case, we set the initial oil price level at US\$60/barrel. In case 1 , we set oil price level one-third below, and one-third and two-thirds above its base level value, which correspond to the oil prices of US\$40, US\$80 and US\$100 per barrel, and then calculate their impacts on the values of the overseas oil project. 
Table 4 Oil Project Values at Different Level of Oil Prices in Case 1

\begin{tabular}{|c|c|c|c|}
\hline \multirow{2}{*}{$\begin{array}{l}\text { Case } 1 \text { The impacts of oil price level } \\
\text { Oil price at } 40 \text { US dollar/barrel }\end{array}$} & \multicolumn{3}{|c|}{ Oil field size } \\
\hline & $\begin{array}{l}\text { Large } \\
(\mathrm{O}-\mathrm{L})\end{array}$ & $\begin{array}{c}\text { Medium } \\
\text { (O-M) }\end{array}$ & $\begin{array}{l}\text { Small } \\
(\mathrm{O}-\mathrm{S})\end{array}$ \\
\hline Project Value (Millions RMB) & 5789.03 & 148.02 & 14.72 \\
\hline $\begin{array}{l}\text { Project Value of Equivalent Oil Production } \\
\text { Capacity (Millions RMB/Millions Barrels per } \\
\text { year) }\end{array}$ & 482.42 & 24.67 & 4.91 \\
\hline Percentage of Paths Abandoned (\%) & 0.420 & 34.540 & 97.660 \\
\hline Project Completion Period (years) & 3.69 & 3.19 & 2.03 \\
\hline Oil price at 80 US dollar/barrel & $\begin{array}{c}\text { Large } \\
(\mathrm{O}-\mathrm{L})\end{array}$ & $\begin{array}{c}\text { Medium } \\
\text { (O-M) }\end{array}$ & $\begin{array}{l}\text { Small } \\
(\mathrm{O}-\mathrm{S})\end{array}$ \\
\hline Project Value (Millions RMB) & 27275.42 & 7057.95 & 2512.59 \\
\hline $\begin{array}{l}\text { Project Value of Equivalent Oil Production } \\
\text { Capacity (Millions RMB/Millions Barrels per } \\
\text { year) }\end{array}$ & 2272.95 & 1176.32 & 837.53 \\
\hline Percentage of Paths Abandoned (\%) & 0.100 & 0.180 & 0.580 \\
\hline Project Completion Period (years) & 3.70 & 3.69 & 3.49 \\
\hline Oil price at 100 US dollar/barrel & $\begin{array}{l}\text { Large } \\
(\mathrm{O}-\mathrm{L})\end{array}$ & $\begin{array}{c}\text { Medium } \\
\text { (O-M) }\end{array}$ & $\begin{array}{l}\text { Small } \\
(\mathrm{O}-\mathrm{S})\end{array}$ \\
\hline Project Value (Millions RMB) & 38523.62 & 14896.06 & 5115.63 \\
\hline $\begin{array}{l}\text { Project Value of Equivalent Oil Production } \\
\text { Capacity (Millions RMB/Millions Barrels per } \\
\text { year) }\end{array}$ & 3210.30 & 2482.68 & 1705.21 \\
\hline Percentage of Paths Abandoned (\%) & 0.100 & 0.160 & 0.420 \\
\hline Project Completion Period (years) & 3.69 & 3.60 & 3.51 \\
\hline
\end{tabular}

From the results shown in Table 4, we can see that changes in the oil price level have significant impacts on the values of the three different sizes of oil fields. The investment risks of O-M and O-S show more sensitivity to oil price level change than that of O-L. The oil price levels also show symmetric impacts on the project values of O-L and O-M. When the oil price level increases by one-third, the project values of O-L and O-M increase by 66.53\% and $113.42 \%$ relative to that of the base case, respectively. When the oil price level decreases by one-third, the project values of O-L and O-M decrease by $62.15 \%$ and $93.90 \%$ relative to that of the base case, respectively. Clearly, the results show equal magnitude of project value change as oil price increases or decreases by the same percentages. However, the oil price levels have an asymmetric impact on the project value of O-S, with the magnitude of the project value change of an oil price increase being larger than that of an oil price decrease (when oil price level increases by one-third, the O-S project value increases by $687.27 \%$, which is far larger than that of 98.01\% when the oil price level decrease by one-third). After 2009, the oil price level has remained at a high level (the level of oil price has been above US\$100/barrel for quite some time). Our results show that if the oil price level 
remains above US\$80/barrel, the investment risks of the three different sizes of oil fields are very small (the investment risks of O-S are only $0.580 \%$ and $0.420 \%$ when oil price levels are at US $\$ 80 /$ barrel and US $\$ 100 / b a r r e l$, respectively). However, the investment risks of O-M and O-S increase dramatically when the oil price level drops to \$US40/barrel: the investment risk of O-M is $34.54 \%$ compared to $0.36 \%$ in the base case and the investment risk of O-S is $97.66 \%$. This means that when the oil price level is low, the company should not invest in O-S because of high investment risk.

\subsubsection{The case under uncertainty of investment environment and exchange rate}

Previous research on oil resource investment evaluation has paid much attention to oil price uncertainty, which may increase the value of an oil project, thus having a positive impact on the oil project valuation. However, other uncertainty factors also exist in overseas oil investment. In this subsection, we will discuss two other uncertainty factors: investment environment and exchange rate.

\subsubsection{The impacts of investment environment}

The base case has already considered the impacts of investment environment and exchange rate uncertainties, basing on the historical data on these two factors. To examine the impacts of the volatilities of these two uncertainty factors, we calculate the oil project value with consideration of changes in these uncertainty factors. In case 2, we first calculate the oil project value with consideration of changes in investment environment uncertainty, by setting the volatility (standard deviation rate) of oil production cost at $20 \%$ and $40 \%$. The correlation coefficients between oil production cost and other uncertainty factors are set at the same values as the base case.

Table 5 Oil Project Values under Uncertainty of Investment Environment in Case 2

\begin{tabular}{|c|c|c|c|}
\hline Case 2 The impacts of investment & & Dil field siz & \\
\hline $\begin{array}{l}\text { Volatility of oil develop cost (investment } \\
\text { environment): } 20 \%\end{array}$ & $\begin{array}{l}\text { Large } \\
(\mathrm{O}-\mathrm{L})\end{array}$ & $\begin{array}{c}\text { Medium } \\
\text { (O-M) }\end{array}$ & $\begin{array}{l}\text { Small } \\
(\mathbf{O}-\mathrm{S})\end{array}$ \\
\hline Project Value (Millions RMB) & 15866.73 & 4263.62 & 177.71 \\
\hline $\begin{array}{l}\text { Project Value of Equivalent Oil Production } \\
\text { Capacity (Millions RMB/Millions Barrels per } \\
\text { year) }\end{array}$ & 1322.23 & 710.60 & 59.24 \\
\hline Percentage of Paths Abandoned (\%) & 0.230 & 0.540 & 24.620 \\
\hline Project Completion Period (years) & 3.69 & 3.60 & 3.27 \\
\hline $\begin{array}{l}\text { Volatility of oil develop cost (investment } \\
\text { environment): } 40 \%\end{array}$ & $\begin{array}{l}\text { Large } \\
(\mathrm{O}-\mathrm{L})\end{array}$ & $\begin{array}{c}\text { Medium } \\
\text { (O-M) }\end{array}$ & $\begin{array}{l}\text { Small } \\
(\mathbf{O}-\mathrm{S})\end{array}$ \\
\hline Project Value (Millions RMB) & 14767.42 & 3442.39 & 61.14 \\
\hline $\begin{array}{l}\text { Project Value of Equivalent Oil Production } \\
\text { Capacity (Millions RMB/Millions Barrels per } \\
\text { year) }\end{array}$ & 1230.62 & 573.73 & 20.38 \\
\hline Percentage of Paths Abandoned (\%) & 0.260 & 0.640 & 38.890 \\
\hline Project Completion Period (years) & 3.64 & 3.58 & 3.10 \\
\hline
\end{tabular}


As shown in Table 5, when we increase the volatility of investment environment, the oil project values in case 2 are smaller for all three oil field sizes than that of the base case. Compared to the base case, when we set the volatility of investment environment at 20\%, the project values of the O-L, O-M, and O-S are shrunk by $4.88 \%$, $6.13 \%$, and $47.34 \%$, respectively. And as the volatility goes up to $40 \%$, the project values of the O-L, O-M, and O-S are then shrunk by $11.47 \%, 24.21 \%$, and $81.88 \%$ compared to that of the base case, respectively. Note in particular that the value of $\mathrm{O}-\mathrm{S}$ in case 2 has decreased dramatically relative to that of the base case. A rise of investment environment volatility will not only decrease the project value, but also increase the investment risk of an overseas oil project. Compared to the base case, the percentages of paths abandoned in O-L and O-M are slightly larger in case 2 than that in the base case, while the percentage of paths abandoned in O-S increases significantly (24.620\% and $38.890 \%$ when investment environment volatility are set at $20 \%$ and $40 \%$, compared to $19.02 \%$ in the base case). As the uncertainty of investment environment is reflected in the oil production cost in the model, the uncertainty of investment environment causes volatility in oil production cost, so its impact on the project value differs from that of commodity price uncertainty. A rise in the oil production cost volatility will add more uncertainty in the expenditure of an overseas oil project, and therefore could have a negative impact on an overseas oil project valuation.

\subsubsection{The impacts of exchange rate}

We then calculate the oil project value with consideration of changes in exchange rate uncertainty. Specifically, in case 3 , we set the volatility (standard deviation rate) of exchange rate at $15 \%$ and $30 \%$. The correlation coefficients between the U.S. dollar exchange rate and other uncertainty factors are set at the same values as the base case.

Table 6 Oil Project Values under Uncertainty of Exchange Rate in Case 3

\begin{tabular}{|c|c|c|c|}
\hline Case 3 The impacts of exchange rate & & il field siz & \\
\hline Volatility of exchange rate: $15 \%$ & $\begin{array}{l}\text { Large } \\
\text { (O-L) }\end{array}$ & $\begin{array}{c}\text { Medium } \\
\text { (O-M) }\end{array}$ & $\begin{array}{l}\text { Small } \\
(\mathrm{O}-\mathrm{S})\end{array}$ \\
\hline Project Value (Millions RMB) & 16899.87 & 4756.41 & 59.79 \\
\hline $\begin{array}{l}\text { Project Value of Equivalent Oil Production } \\
\text { Capacity (Millions RMB/Millions Barrels per } \\
\text { year) }\end{array}$ & 1408.32 & 792.74 & 19.93 \\
\hline Percentage of Paths Abandoned (\%) & 0.080 & 0.120 & 12.360 \\
\hline Project Completion Period (years) & 3.65 & 3.57 & 3.34 \\
\hline Volatility of exchange rate: $30 \%$ & $\begin{array}{c}\text { Large } \\
(\mathrm{O}-\mathrm{L})\end{array}$ & $\begin{array}{c}\text { Medium } \\
\text { (O-M) }\end{array}$ & $\begin{array}{l}\text { Small } \\
(\mathrm{O}-\mathrm{S})\end{array}$ \\
\hline Project Value (Millions RMB) & 30092.03 & 11391.88 & 3303.33 \\
\hline $\begin{array}{l}\text { Project Value of Equivalent Oil Production } \\
\text { Capacity (Millions RMB/Millions Barrels per } \\
\text { year) }\end{array}$ & 2507.67 & 1898.65 & 1101.11 \\
\hline Percentage of Paths Abandoned (\%) & 0.490 & 0.720 & 1.270 \\
\hline Project Completion Period (years) & 3.63 & 3.55 & 3.41 \\
\hline
\end{tabular}


Our results in Table 6 show that when we increase the volatility of exchange rate, the project values of the O-L and $\mathrm{O}-\mathrm{M}$ in case 3 are larger than that of the base case. Compares to the base case, when we set the volatility of exchange rate at $15 \%$, the project values of the O-L and O-M are increased by $1.31 \%$ and $4.72 \%$. And when we set the volatility at 30\%, the project values of the O-L and O-M rise dramatically, increasing by $80.39 \%$ and $150.80 \%$ compared to that of the base case. With project value increases, the investment risks of the O-L and O-M in case 3 are all increased as the volatility of exchange rate increases (the investment risks of the O-L and O-M are 0.080\% and $0.120 \%$ when the volatility of exchange rate is set at $15 \%$, and are $0.490 \%$ and $0.720 \%$ when the volatility of exchange rate is set at 30\%, which are all larger than that of the base case). Note in particular that the project value of O-S in case 3 has first decreased and then increased as the volatility of exchange rate increases (the value of O-S is decreased by $82.28 \%$ when exchange rate volatility is set at $15 \%$, and is increased by $878.90 \%$, compared to that of the base case when exchange rate volatility is set at 30\%). As we set the U.S. dollar exchange rate along a trend of moving down in the long term in the base case, this downside trend causes a decline of cash flow converted into the oil company's domestic currency, which may have a negative impact on the overseas oil project valuation. But the increase of exchange rate volatility will also increase the value of oil projects, and this impact is different from that of investment environment volatility.

In case 3, as we mentioned above, the results for the O-S seem unusual to that of the O-L and O-M. So we undertake a sensitivity analysis of the O-S value by examining the volatility of exchange rate from $15 \%$ to $45 \%$. 
Figure 3 Sensitivity Analysis of O-S to Exchange Rate Volatility

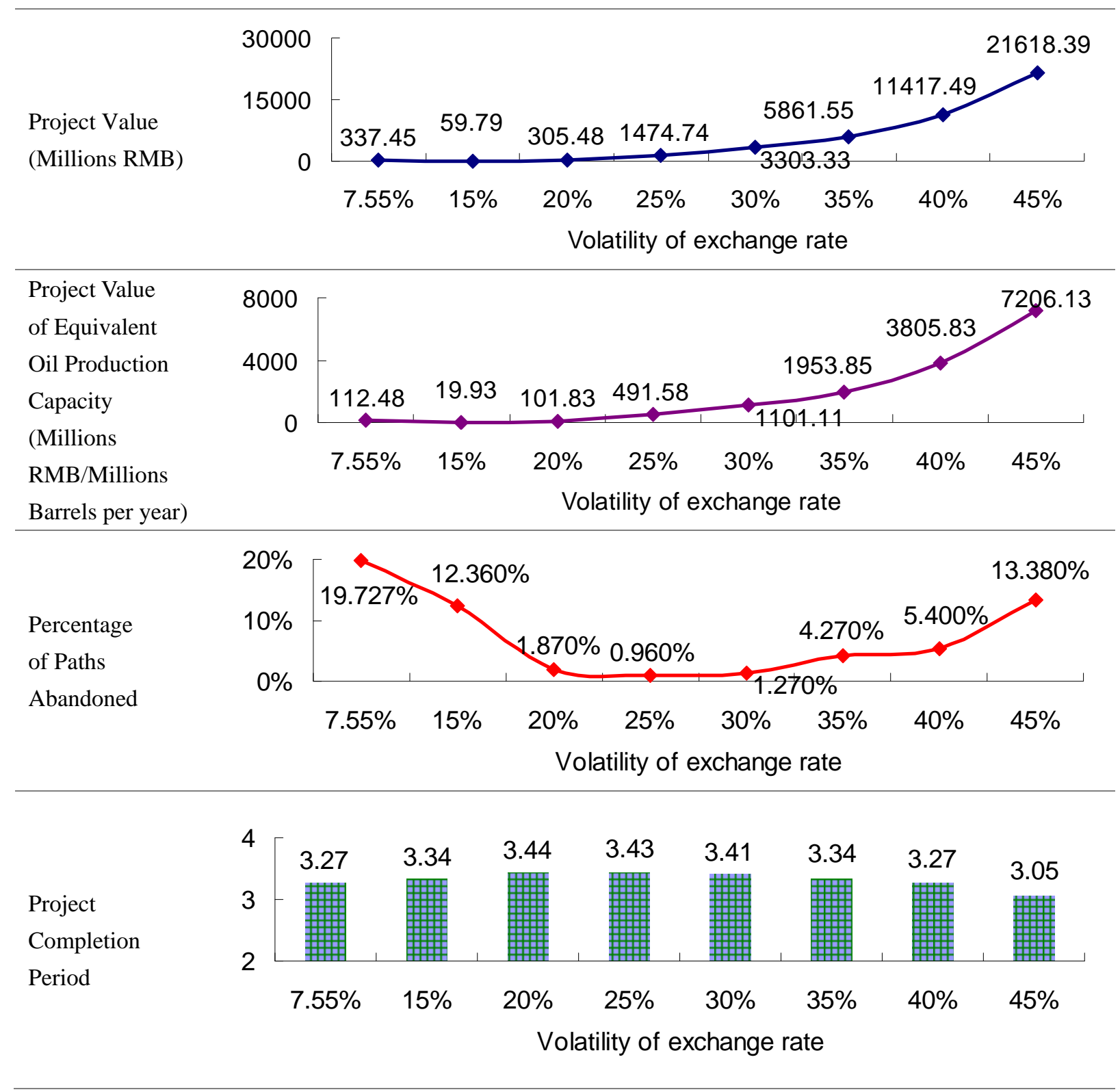

From Figure 3 we can see that, for project value of O-S, when we change the volatility of exchange rate from $7.55 \%$ to $45 \%$, there is an inflection point of the value when the exchange rate volatility is $15 \%$. As the volatility increase from $7.55 \%$ to $15 \%$, the value of O-S decreases from 337.45 millions RMB to 59.79 millions RMB. And as the volatility increase from 15\% to 45\%, the value of O-S increases from 59.79 millions RMB to 21618.39 millions RMB, which shows an obvious upward trend (as the exchange volatility increases from $15 \%$ to $30 \%$, the project values of the O-L and O-M have increased by $78.06 \%$ and $139.51 \%$. Meanwhile the O-S has increased by $5424.71 \%)$. Then we look at the investment risk, as an exchange rate volatility increases, it also shows a trend of decrease first and then increase. But the inflection point of percentage of paths abandoned is when the exchange rate 
volatility is $25 \%$, which is not synchronized with that of the project value. So the valuation of the O-S is more complex and sensitive to the changes in exchange rate volatility.

Uncertainties of investment environment have a negative impact on overseas oil project valuation and to some extent decrease the value of an overseas oil project. This effect is opposite to the effect of exchange rate uncertainty. And the increase in the volatilities of both investment environment and exchange rate will increase the investment risk of overseas oil projects. Moreover, the impacts of the investment environment and exchange rate differ, depending on the sizes of oil fields. The impacts of investment environment and exchange rate on O-S are much larger than those on O-L and O-M. This means the project value of O-S is more complex and sensitive to the change of these two uncertainty factors. Therefore, the investment environment and exchange rate are also important considerations for overseas oil investment activities in the countries where most of their overseas oil projects are classified as small sized oil fields. It should be pointed out that our estimates of the investment environment and exchange rate volatilities have considered the effects of correlation coefficients which are based on their historical data. However, as the volatilities of these two uncertainty factors rise, the correlation coefficients may change. So assuming these coefficients remain unchanged may to some extent lead to the inaccuracy of the results. To mitigate this effect, we set the high volatility of these factors in order to illustrate the trend of project value changes as investment environment and exchange rate volatilities increase.

\subsubsection{The case under oil resource tax systems}

Oil resource tax systems can be classified into two major categories: the royalty tax system and the PSC system. Under the royalty system, a fixed percentage agreed between a government and the oil company is charged on the gross oil production. The PSC system is similar to the royalty system except that the rate is applied after consideration of production costs. The PSC system predominates in Indonesia, the investee country in our paper. In recent years, oil resource investee countries have introduced different production sharing rates according to oil field production capacity to encourage foreign oil companies to develop their medium or small sized oil fields. Some countries also levy a windfall profits tax according to the level of oil price. In this section, we simulate the impacts of production sharing rates and windfall profits tax on the value of an overseas oil project.

\subsubsection{The impact simulation of ladder production sharing rates}

We first simulate the production sharing rates (case 4). As the production sharing rate (cost oil limit) is related to oil field quality, the oil company will negotiate with investee country to define the cost oil limit in PSC at the initial stage. In case 4 we keep the investee country's cost oil limit in the O-M unchanged, but change the rate in the O-S

from 2.00 to 2.40 million barrels/year (an increase) and in the O-L from 8.00 to 6.00 million barrels/year (a decrease). Our results in Table 7 show that when the cost oil limit rate increases from $66.67 \%$ to $80.00 \%$, the project value of O-S increases by $217.63 \%$. 
Table 7 Oil Project Values with Resource Ladder Production Sharing Rate in Case 4

\begin{tabular}{lccc}
\hline Case 4 Resource Production Sharing & \multicolumn{3}{c}{ Oil field size } \\
\hline Investee Country & $\begin{array}{c}\text { Large } \\
(\mathbf{O}-\mathbf{L})\end{array}$ & $\begin{array}{c}\text { Medium } \\
(\mathbf{O}-\mathbf{M})\end{array}$ & $\begin{array}{c}\text { Small } \\
(\mathbf{O}-\mathbf{S})\end{array}$ \\
\hline Project Value (Millions RMB) & 10447.92 & 4542.24 & 1071.85 \\
\hline $\begin{array}{l}\text { Project Value of Equivalent Oil Production } \\
\text { Capacity (Millions RMB/Millions Barrels per }\end{array}$ & 870.66 & 757.04 & 357.28 \\
year) & & & \\
\hline Percentage of Paths Abandoned (\%) & 0.320 & 0.360 & 3.200 \\
\hline Project Completion Period (years) & 3.70 & 3.58 & 3.47 \\
\hline
\end{tabular}

By incorporating different production sharing rates in the model, the project value of O-L decreases significantly, the project value of equivalent oil production in the O-L being only slightly larger than that in the O-M. So the different oil production sharing rates can narrow the diversity between different oil fields, providing greater benefits to the investee country with large sized oil fields.

\subsubsection{The impact of windfall profits tax}

We then simulate the windfall profits tax. In case 5, the threshold price of windfall profits tax is set at \$US70/barrel and the tax rate at $20 \%$.

Table 8 Oil Project Values under Windfall Profits Tax in Case 5

\begin{tabular}{lccc}
\hline Case 5 Windfall profit tax & \multicolumn{3}{c}{ Oil field size } \\
\hline Investee Country & $\begin{array}{c}\text { Large } \\
\text { (O-L) }\end{array}$ & $\begin{array}{c}\text { Medium } \\
\text { (O-M) }\end{array}$ & $\begin{array}{c}\text { Small } \\
\text { (O-S) }\end{array}$ \\
\hline Project Value (Millions RMB) & 13202.16 & 2548.72 & 92.79 \\
\hline $\begin{array}{l}\text { Project Value of Equivalent Oil Production } \\
\text { Capacity (Millions RMB/Millions Barrels per } \\
\text { year) }\end{array}$ & 1100.18 & 424.79 & 30.93 \\
\hline Percentage of Paths Abandoned (\%) & 0.600 & 0.880 & 53.720 \\
\hline Project Completion Period (years) & 3.66 & 3.58 & 2.91 \\
\hline
\end{tabular}

The results in Table 8 show windfall profits tax also has a negative impact on the oil project value. The project values of the three sizes of oil fields decrease, especially that of the O-S whose percentage of paths abandoned significantly rises to $53.720 \%$. Therefore, in overseas oil investment, small sized oil fields will be most affected by the levy of windfall profits tax, with the investment risk having been increased by $172.32 \%$.

As the model is based on Monte Carlo simulation using a large sample, the model can better describe complex oil 
resource tax systems among different investee countries. Therefore, the model has good applicability for an evaluation of overseas oil investments.

\section{Conclusions and further work}

With the world's oil use set to rise, companied with increasing world's oil prices, adding new capacities to world oil supplies via oil overseas investment is seen as beneficial to all, and needs thus to be encouraged and appreciated. However, making overseas oil investment is a complex process, and a number of uncertainty factors play important roles in overseas oil development activities. Thus, the evaluation of overseas oil project should take into consider not only the uncertainties of oil price and investment cost, but also investment environment and exchange rate uncertainties. To help investors to make the informed decision in overseas oil investment, our paper first establishes an overseas oil investment evaluation model. Given that real options analysis is considered to better reflect the flexibility and impacts of uncertainty factors on the value of overseas oil investment than the NPV method, our model has considered a number of uncertainty factors by applying real options analysis and is solved by the LSM. We then employ the model to study and compare the values of three typical sized oil fields (large, medium, small) in overseas oil investment.

Our results show that changes in oil price, exchange rate, and investment environment have different impacts on different sized oil fields. In general, the project value and investment risk of O-S are more sensitive to changes in the uncertainty factors than those of O-L and O-M. For example, when the oil price level is US\$40/barrel, it is not worth investing in O-S. The investment risk of O-L is very small. By contrast, changes in the uncertainty factors only have limited impacts on the project value and investment risk of O-L. Therefore, O-L is the preferred choice for an overseas oil investment.

We also find that the investment risk of overseas oil investment may be underestimated if no consideration is given of the impacts of exchange rate and investment environment. Previously, the investor paid much attention to output commodity prices, tax rate, and interest rate, which have a direct relationship to investment evaluation. But our results show that the uncertainty in investment environment has a negative impact on overseas oil project valuation and shrinks the value of overseas oil project. Although the increase of exchange rate uncertainty can increase the value of overseas oil project, the investment risk will increase as well. Thus, when the exchange rate fluctuates significantly, the investor may need to consider some foreign exchange transactions in order to hedge the risk of exchange rate. Moreover, the valuation of O-S, to some extent, is more complex and sensitive due to the changes in investment environment and exchange rate uncertainties. Therefore, making overseas oil investment in small-sized oil fields should not only consider oil prices, tax rates, and interest rates, which are directly related to investment evaluation, but also should consider the investment environment and exchange rates in investment decisions.

Furthermore, our analysis shows that there is an important trade off between oil resource investee country and overseas oil investor. On the one hand, to encourage foreign oil companies to develop their medium or small seized oil fields, oil resource investee countries prefer to adjust their resource tax systems to balance the resource valuation diversity among different size oil fields, in particular by means of production sharing rates. On the other hand, with oil price fluctuation in recent years, to obtain more oil development benefits, some investee countries also levy a windfall profits tax so that more oil revenue can remain in their country. Therefore, in the oil investment negotiation between the oil company and investee country, the oil company should first try to the extent possible to increase the 
cost oil limit in PSC for O-M and O-S in order to obtain more benefits in the development of such fields. Our results show that if the cost oil limit increases, the project value of O-S increases. Second, as small sized oil fields are more sensitive to windfall profits tax, the oil company also needs to avoid the term of a windfall profits tax in oil development contract in order to further reduce the investment risk of overseas small sized oil fields.

Our model has incorporated a number of uncertainty factors to better reflect the reality of overseas oil investment. However, making overseas oil investment is a complex decision process. Although the real options model established in this paper adds extra functionality over existing models such as the NPV method, there are some limitations. First, the model does not consider the uncertainty of oil production capacity. In general, nearly all oil fields will to a varying degree suffer production decline. Second, a lot of oil companies are involved in overseas oil exploration activities. Therefore, how to combine the exploration process into our model is also an important issue. These issues are examples of interesting issues that need to be addressed in our future work.

\section{Acknowledgments}

Support from the National Natural Science Foundation of China under Grant No. 70825001 and No. 71133005 is greatly acknowledged.

\section{References}

1. Aguerrevere, F.L. 2003. Equilibrium Investment Strategies and Output Price Behavior: A Real-Options Approach. Review of Financial Studies 16 (4): 1239-1272.

2. Brennan, M.J., Schwartz, E.S. 1985. Evaluating Natural Resource Investments. J. Business 58: 135-157.

3. Bar-Ilan, A., Strange, W.C. 1996. Investment Lags. American Economic Review 86 (3), 610-622.

4. Conrad, J.M., Kotani, K. 2005. When to drill? Trigger prices for the Arctic National Wildlife Refuge. Resource and Energy Economics 27: 273-286.

5. Copeland, T.E., Antikarov, V. 2005. Real Options: Meeting the Georgetown Challenge. Journal of Applied Corporate Finance 17(2): 32-51

6. Dixit, A.K., Pindyck, R.S. 1994. Investment Under Uncertainty. Princeton University Press, Princeton NJ.

7. Costa Lima, G.A., Suslick, S.B. 2006. Estimating the volatility of mining projects considering price and operating cost uncertainties. Resource Policy 31: 86-94.

8. Davisa, G.A., Owens, B. 2003. Optimizing the level of renewable electric R\&D expenditures using real options analysis. Energy Policy 31: 1589-1608.

9. Fan, Y., Zhang, Y.J., Tsai, H.T., Wei, Y.M. 2008. Estimating 'value at risk' of crude oil price and its spillover effect using the GED-GARCH approach. Energy Economics, 30 (6): 3156-3171.

10. Fan, Y., Zhu, L. 2010. A Real Options Based Study on Overseas Oil Investment and its application in China's Oversea Oil Investment. Energy Economics 32: 627-637.

11. International Energy Agency (IEA). 2003. World Energy Investment Outlook. OECD/IEA, Paris.

12. International Energy Agency (IEA). 2006. World Energy Outlook. OECD/IEA, Paris.

13. Kulatilaka, N., Perotti, E.C.. 1998. Strategic growth options. Management Science 44 (8): 1021-1031.

14. Longstaff, F.A., Schwartz, E.S. 2001. Valuing American Options by Simulation: A Simple Least Square Approach. Review of Financial Studies 14(1): 113-147. 
15. Majd, S., Pindyck., R.S. 1987. Time to build, option value, and investment decisions. Journal of Financial Economics 18 (1): 7-27.

16. McDonald, R., Siegel, D. 1986. The value of waiting to invest. Quarterly Journal of Economics 101(4): 707-727.

17. Merton, R.C. 1973. The theory of rational option pricing. Bell J. Economics and Mgmt. Sci. 4: 141-183.

18. Myers, S.C. 1977. Determinants of Cooperate Borrowing. Journal of Financial Economics 5: 147-175.

19. Myers, S.C. 1984. Finance theory and financial strategy. Interfaces 14: 126-137.

20. Nordal, K.B. 2001. Country risk, country risk indices and valuation of FDI: a real options approach. Emerging Markets Review 2: 197-217.

21. Paddock, J.L., Siegel, D.R., Smith, J.L. 1988. Option valuation of claims on real assets: the case of offshore petroleum leases. Quarterly Journal of Economics 103: 479-508.

22. Pindyck, R.S. 1999. The long-run evolution of energy prices. MIT-CEEPR working papers, available at: http://mit.dspace.org/handle/1721.1/45087.

23. Ross, S. 1978. A simple approach to the valuation of risky streams. Journal of Business 51(3): 453-475.

24. Sarkar, S. 2000. On the investment-uncertainty relationship in a real options model. Journal of Economic Dynamics and Control 24: 219-225.

25. Schwartz, E.S. 2004. Patents and R\&D as Real Options. Economic Notes by Banca Monte dei Paschi di Siena SpA, 33: 23-54.

26. Schwartz, E.S., Trolle, A.B. 2010. Pricing expropriation risk in natural resource contracts - A real options approach. In William Hogan and Federico Sturzenegger (eds.), The Natural Resource Trap, MIT Press.

27. Smit, H.T.J., Trigeorgis, L. 2004. Strategic investment, real options and games. New Jersey: Princeton University Press.

28. Smith, J.E., McCardle, K.F. 1996. Valuing oil properties: integrating option pricing and decision analysis approaches. Operations Research 46: 198-217.

29. Smith, J.E., McCardle, K.F. 1999. Options in the real world: lessons learned in evaluating oil and gas investments. Operations Research 47: 1-15.

30. Thompson, A.C. 2001. The Hotelling Principle, backwardation of futures prices and the values of developed petroleum reserves - the production constraint hypothesis. Resource and Energy Economics 23: 133-156.

31. Tang, W.Q., Wu, L.B., Zhang, Z.X. 2010. Oil price shocks and their short- and long-term effects on the Chinese economy. Energy Economics 32 (Supplement 1): S3-S14.

32. Wu, L.B., Li, J., Zhang, Z.X. 2011. Inflationary Effect of Oil-price Shocks in an Imperfect Market: A Partial Transmission Input-output Analysis, Fondazione Eni Enrico Mattei Working Paper No. 579, Berkeley Electronic Press. 